Content list available at: https:/openbiomedicalengineeringjournal.com

RESEARCH ARTICLE

\title{
A Development Machine for Measuring the Precision and the Response Time of Punches
}

Tossaphon Jaysrichai ${ }^{1,{ }^{*}}$, Kachonsak Srikongphan ${ }^{2}$ and Pornchalit Jurarakpong ${ }^{3}$

${ }^{1}$ Faculty of Physical Therapy, Srinakharinwirot University, Ongkharak, Thailand

${ }^{2}$ Faculty of Engineering, Srinakharinwirot University, Ongkharak, Thailand

${ }^{3}$ Sport Science Research Division, Sport Authority of Thailand, Bangkok, Thailand

\begin{abstract}
:
Objective:

To develop and evaluate the device for measuring precision (in percentage) and response time (in seconds) of punches.

Methods:

Researchers cooperated with Sports Authority of Thailand and the Amateur Boxing Association of Thailand in development.

Results:

Robo-Boxing Trainer machine consisted of four targets. Each punching target has eight sensors and eight LED lights. Operating software, which programmed by PLC-CX programmer and DOPSoft (delta), can set the punching series and alarm signals. It recorded the response time from the starting signal to making contact with the target, calculating precision in percentage. This software could be set and recorded maximal 40 series and maximal 100 punches in each punching series. Researchers compared the accuracy of counting time with Digital Oscilloscope and tested the efficiency of sensors' cutting signal. This study found the counting time to be of high accuracy $(100 \%$ and $98.8 \%)$. The cutting sensors' signal test found to be efficient.

Conclusion:

Robo-Boxing Trainer machine, which is high in accuracy, may help to test and improve a boxer's skills. Also, it can apply to train for other related sports.
\end{abstract}

Keywords: Boxing, Response time, Innovative sport, Punch precision, Boxing trainer, Sport engineering, Sport technology.

\begin{tabular}{l|l|l|l} 
Article History & Received: September 12, 2019 & Revised: November 29, 2019 & Accepted: November 29, 2019
\end{tabular}

\section{INTRODUCTION}

Amateur boxing in Thailand is well renowned and Thai boxers across the country are hopeful to one day make it to the Olympics to win gold. The key to their success is to practice boxing daily. A boxer's training program's purpose is to improve the performances of strengthening, endurance, speed, cardiovascular fitness etc. After the training, it should have the method for evaluating the boxers' performance. If a boxer has good methods or a device that can give feedback with quantitative data, it can help athletes to perform at a high standard in their training program to the best effect.

\footnotetext{
* Address correspondence to this author at Srinakharinwirot University, Physical Therapy, Rangsit-Nakhon Nayok Road, Ongkharak, Thailand; Tel: 945935464; E-mail: toss.jay@gmail.com
}

Speed and the precision of punching are necessary for boxers. Amateur boxers always train punching technique with trainers. An effective punch incorporates speed and power. Time that used to movement from the starting arm movement until the punch hitting target is called the Movement Time. Reaction Time is the body's response to the stimulation that occurs. The reaction time and the movement time conjoin to the response time. Reaction time is an important skill which has been used in many sports including boxing. Carlin JA, in 1986, created an innovation for evaluating reaction time and force in boxers [1 - 8]. However, this development focused on the measuring reaction time and precision of punch [9]. The effect on muscle power training can improve a fast punch, however, the precision of punching may be improved after training. The precision of punch means a striking fist to the 
precise target [10].

A device to give quantitative data of speed and precision of punch is very useful for a boxer's training. The researchers collaborated with the Sports Authority of Thailand to develop a device for measuring the response time (in seconds) and the precision (in percentage) of boxers' punches that is called "Robo-Boxing Trainer". The photo sensors (U-shaped Micro Photoelectric Sensor Model PM-25/45/65 SERIES, Panasonic Industrial Devices SUNX Co., Ltd., Japan), were used to add on each punching target. Eight photo sensors were designed to be cut-off simultaneously to signal when the target had been impacted. This device was designed to record the time that started from the opening stimulus (light and sound) to the cutting of the signal. Moreover, this device was set independently to the sequence of target. That may be a benefit to apply for testing or training boxers. The purpose was to develop a device to measure continuously the precision (in percentage) and response time (in seconds) of punch, and also tested the accuracy of the counting timer and the cutting-off sensor area.

\section{METHODS}

Firstly, the researchers made an appointment with the teams from Sport Science Research Division, Sports Authority of Thailand and the coaches from the Amateur Boxing Association of Thailand. The researchers presented a conceptual idea to develop an innovation for training the amateur boxers. The first draft was purposed to develop a device for measuring impact force and reaction time of punches. After that, our team gathered the suggestions from coaches and the sport scientists from the Sports Authority of Thailand. We welcomed any suggestions in order and to adjust our design of the device.
In the second meeting, our team presented the adjusted device's design, the specifications of devices and the conceptual frameworks to the teams from Sport Science Research Division, Sports Authority of Thailand and the coaches from the Amateur Boxing Association of Thailand. After the meeting, the researchers' plan was approved and we attained the budget from the Sports Authority of Thailand.

\section{RESULTS}

Robo-Boxing Trainer machine could be divided into four main components (Fig. 1) that consisted of the main pillar with punching targets (Fig. 1a), the back-stays (Fig. 1b), the partially-fixed support (Fig. 1c), and the base-plate (Fig. 1d).

The main pillar with punching targets, there were four punching targets and a main controlled box. Total height of main pillar was 1.89 meters. Four punching targets were for the straight punch, the right hook punch, the left hook punch, and the upper-cut punch. The level position of punching target could be adjusted between 1.25 meters to 1.55 meters relevant to the users' height. The discrimination in each height step was 0.05 meters. Main Controller Unit was for the electrical system and the touch-screen monitor (HMI DOP-B03E211 480x272 size $4.3 \mathrm{inch}$ ). The touch-screen monitor was used to turn-on or turn-off the device, to set the parameters and to display the result. The back-stays was used to support the device (Fig. 1b). The partially-fixed support, designed in an $\mathrm{H}$ - shape with a wide front-base, was used to support the device (Fig. 1c). The base-plate, which was the 1.3 meters of steel-plate sealed with non-slip rubber, was used for the boxers to step on during the test. Robo-Boxing Trainer machine was the underlying process to communicate with the patent from the Department of Intellectual Property, Thailand (no. 1701001185, 7 March 2017).

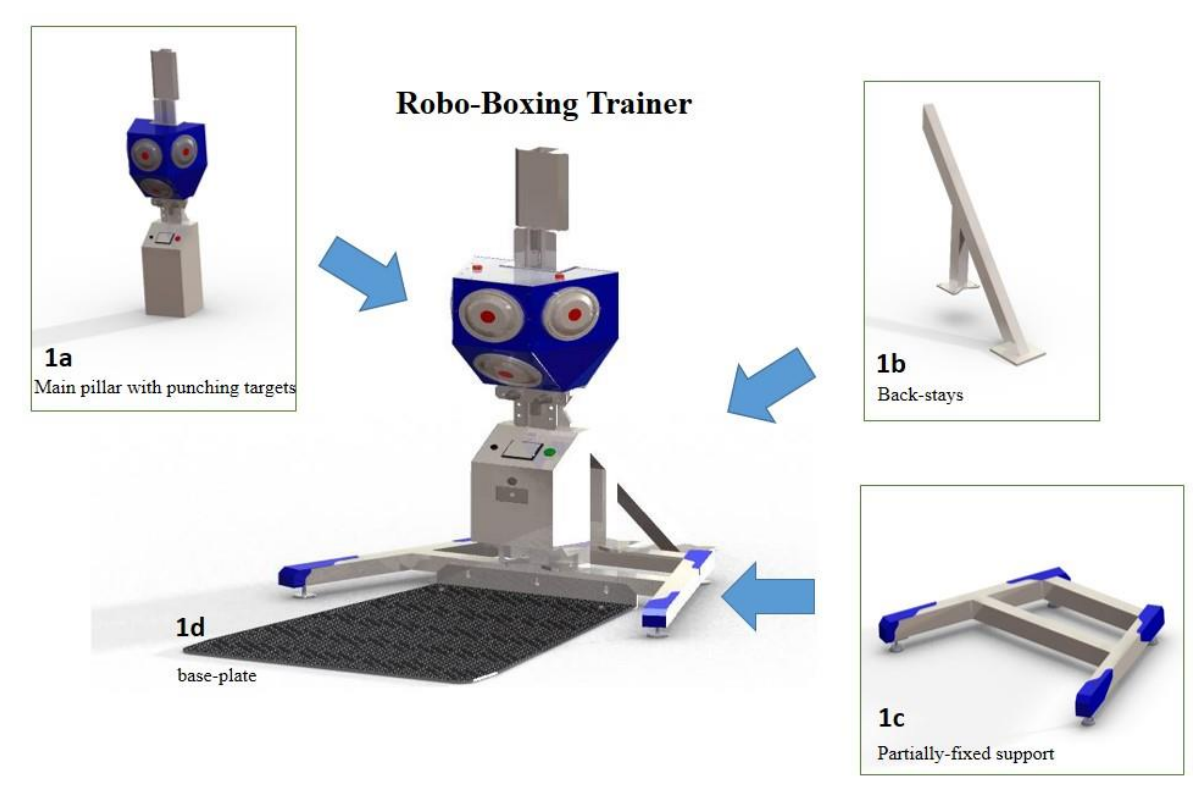

Fig. (1). shows the framework of Robo-Boxing Trainer machine; (a) shows the main pillar with punching targets, (b) shows the back-stays, (c) the partially-fixed support, and (d) the base-plate. 
These punching targets were designed similar to the Wall Mount Punching Bag that is common boxing target in a gym. The diameter of punching targets was 20 centimeters. It was convex style and also had the diameter for impact area of 15 centimeters.

In the punching target, there were the eight LED super bright white lights, four shock-absorption springs, and eight photo-sensors (U-shaped Micro Photoelectric Sensor Model PM-25/45/65 SERIES, Panasonic Industrial Devices SUNX Co., Ltd., Japan). The photo sensors were arranged counterclockwise positions at the edge of the punching target (15 centimeters from the center). When impact is made on punching targets, photo-sensors was activated and was the resulting in signal transmission. The punching precision was calculated from the amounts of times the sensors were cut off within simultaneously 0.02 seconds and also reported in the percentage of precision.

$$
\text { Percentage of precision }=\frac{\text { Number of } \text { cutting }- \text { off sensors }}{\text { Total sensors } \in \text { each punching target }} X 100 \text { (1) }
$$

The operating software of Robo-Boxing Trainer machine was programmed by using PLC-CX programmer version 6.1 software (Omron Corporation, USA) and the DOPSoft (delta) software version 1.01 .08 was used to create a touchscreen function of the monitor.

The operating software could create the punching series for testing and record into the internal memory. The maximum recordings were 40 series and also had 100 punching slots in each punching series. The A-target on software referred that the left punching target that was normally for left hook punch. The B-target referred that the center punching target that was normally for the straight punch. The $\mathrm{C}$-target referred that the right punching target that was normally for the right hook punch. The D-target referred that the center-down punching target that was normally for the upper-cut punch. The duration of turned-on LED lights on punching targets could be set independently from 0.01 second to 99.99 seconds. The LED lights turned on until the time-out or the impact from the punching force turned the LED lights off. The new series of punching test could be recorded into the internal memory by using “จัดเก็บ " command. The "เรียก" command was used to recall the series of punching test in memory and also press the "ทดสอบ" command when the user needed to start the punching test. (Fig. 2) This software had the " ตรวจเป้า " command to be used for checking the status of the photo-sensor and LED light on punching target.

The punching test began after pressing the "เริ่มต้น" command on the software or the green button on the machine. Fig. (3) represented the resulting screen on software. File name is displayed on the top of the screen. The A, B, C and D block on the right screen represented the punching targets on the machine. The table on left screen was the reporting table. The five columns represented the rank, the punching target, the intime (o) / miss (x), the response time (in seconds), and the percentage of precision (in percentage). The testing protocol was stopped by two methods; the first was to complete the protocol and the second was to press the "หยุด " command on software or to press the green button.

If the user did not press the "จับเวลา " command that referred to turn off the reaction time mode, the device was reported only the percentage of precision values. For printing out reports, the user should connect the Robo-Boxing Trainer machine and computer via LAN cable. The output data, which was in the ASCII file type, was loaded into the computer and could be opened in Microsoft Excel. The flowchart of the operating system in the Robo-Boxing Trainer machine is shown in Fig. (4).

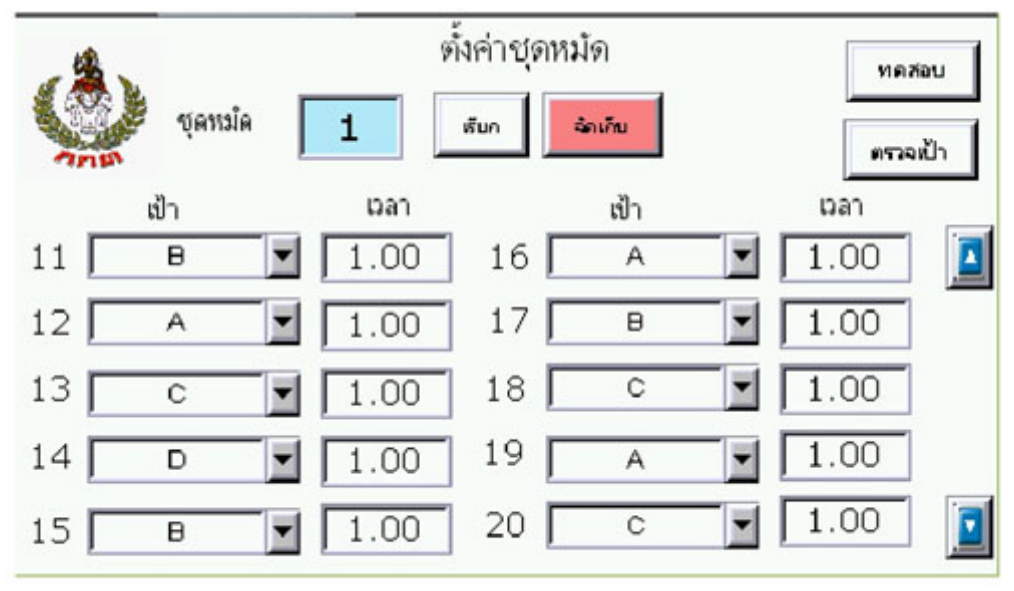

Fig. (2). Shows the setting template of punching test program. 


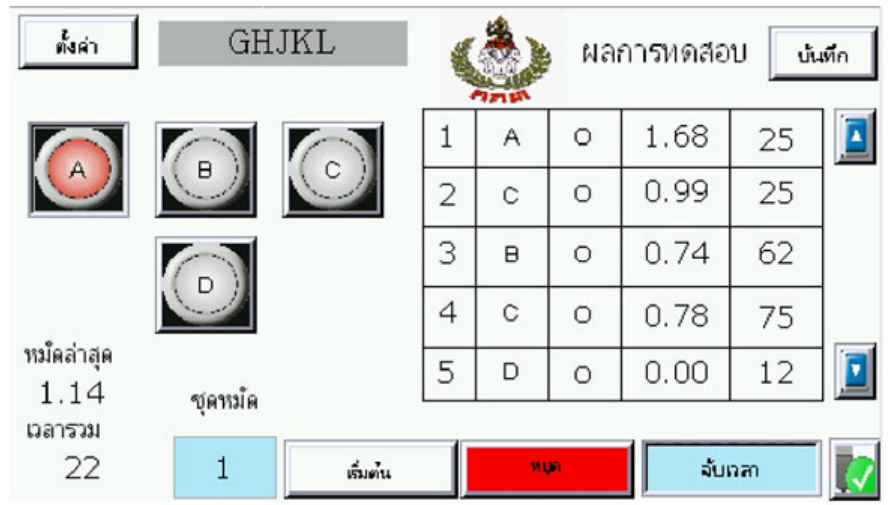

Fig. (3). Shows the testing template of punching test program.

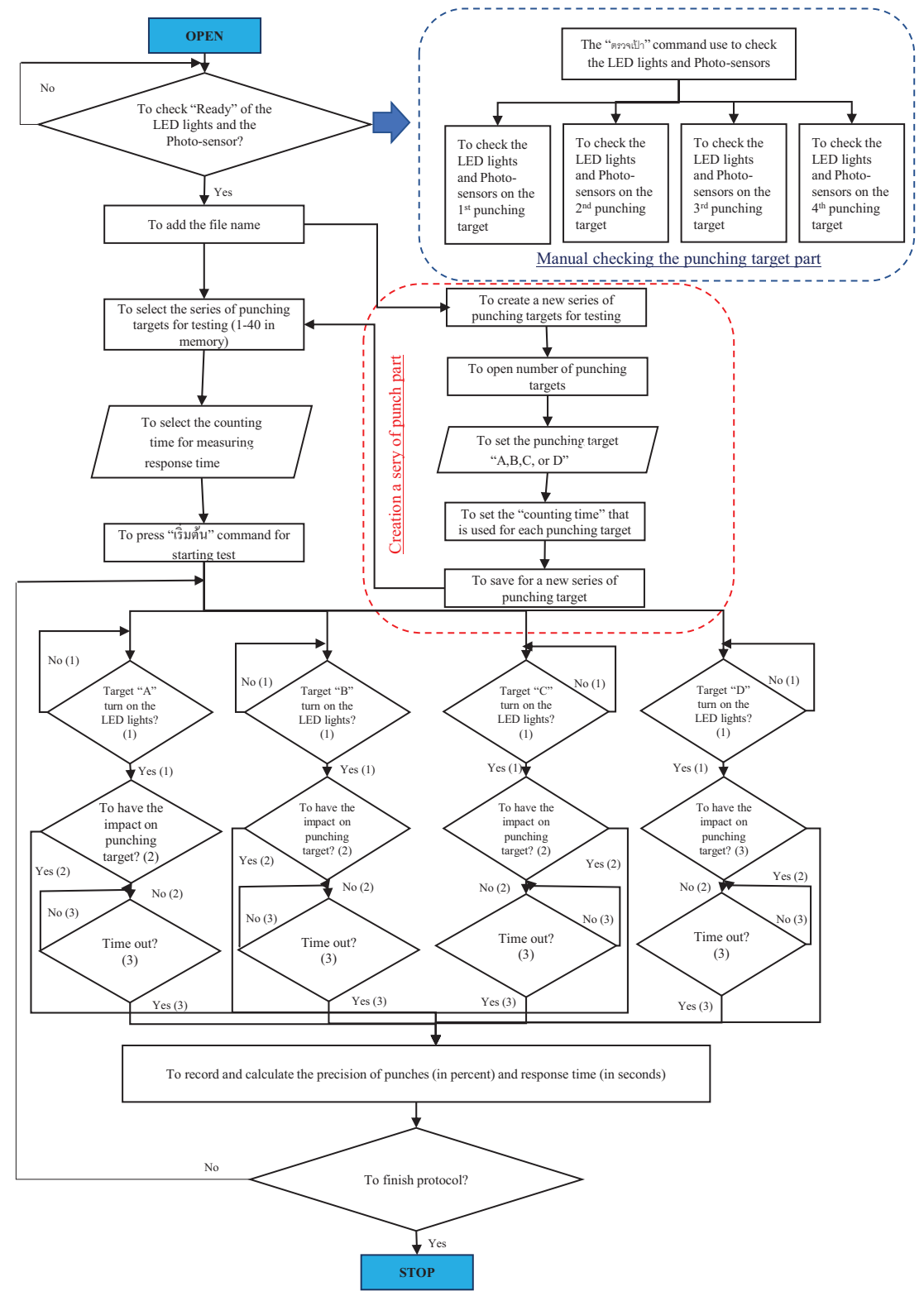

Fig. (4). Shows the flowchart of operating system in the Robo-Boxing Trainer machine. 
The researchers tested the accuracy of the counting timer and the cutting-off sensor area. Firstly, the counting timer system that was set into Robo-Boxing Trainer machine for measuring the response time tested accuracy with Digital Oscilloscope (Yokogawa DL1520 Digital Oscilloscope, Japan). The researchers linked the electrical signal between RoboBoxing Trainer machine and the Digital Oscilloscope. The counting timer was tested from a total 15 attempts; 5 times of 10 second counts and 10 times of cutting time from the sensors. After that, the average, the percentage of error, and the percentage of accuracy was calculated for comparison between Robo-Boxing Trainer machine and the Digital Oscilloscope (Fig. 5) (Table 1), Equ-(2-4)

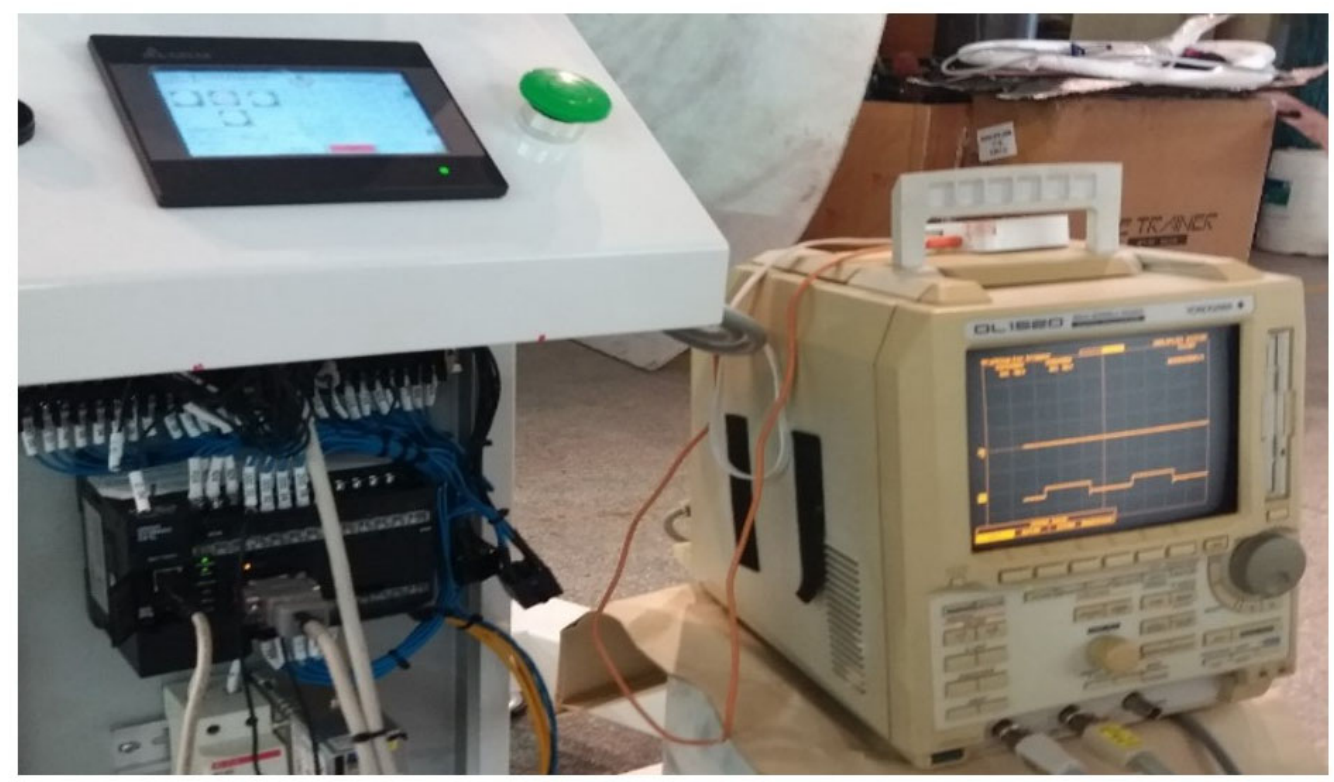

Fig. (5). Shows the counting time test between Robo-Boxing Trainer machine and the Digital Oscilloscope.

Table 1. Revealed the comparison values of counting time between Robo-Boxing Trainer and the Digital Oscilloscope.

\begin{tabular}{|c|c|c|c|c|c|c|c|}
\hline Test & No. & $\begin{array}{c}\text { Counting Time } \\
\text { (seconds) from } \\
\text { Robo-Boxing } \\
\text { Trainer }\end{array}$ & $\begin{array}{c}\text { Counting Time } \\
\text { (seconds) from } \\
\text { Digital } \\
\text { Oscilloscope }\end{array}$ & $\begin{array}{l}\text { Different } \\
\text { Values } \\
\text { (seconds) }\end{array}$ & $\begin{array}{l}\text { Absolute } \\
\text { Different } \\
\text { values } \\
\text { (seconds) }\end{array}$ & $\%$ Error & \%Accuracy \\
\hline \multirow[b]{2}{*}{ - } & 1 & 10 & 10 & 0 & 0 & 0 & 100 \\
\hline & 2 & 10 & 10 & 0 & 0 & 0 & 100 \\
\hline $\begin{array}{l}\text { Counted } 10 \\
\text { seconds test }\end{array}$ & 3 & 10 & 10 & 0 & 0 & 0 & 100 \\
\hline \multirow{3}{*}{-} & 4 & 10 & 10 & 0 & 0 & 0 & 100 \\
\hline & 5 & 10 & 10 & 0 & 0 & 0 & 100 \\
\hline & \multicolumn{3}{|c|}{ Average } & 0 & 0 & 0 & 100 \\
\hline \multirow{4}{*}{ - } & 1 & 1.32 & 1.34 & -0.015 & 0.015 & 1.49 & 98.51 \\
\hline & 2 & 1.29 & 1.32 & -0.023 & 0.023 & 2.27 & 97.73 \\
\hline & 3 & 2.67 & 2.7 & -0.011 & 0.011 & 1.11 & 98.89 \\
\hline & 4 & 0.92 & 0.94 & -0.021 & 0.021 & 2.13 & 97.87 \\
\hline $\begin{array}{l}\text { Cutting time } \\
\text { from the } \\
\text { sensors test }\end{array}$ & 5 & 0.99 & 0.98 & 0.010 & 0.010 & 1.02 & 98.98 \\
\hline \multirow{6}{*}{ - } & 6 & 1.51 & 1.52 & -0.007 & 0.007 & 0.66 & 99.34 \\
\hline & 7 & 2.02 & 2.05 & -0.015 & 0.015 & 1.46 & 98.54 \\
\hline & 8 & 0.85 & 0.86 & -0.012 & 0.012 & 1.16 & 98.84 \\
\hline & 9 & 1.48 & 1.48 & 0.000 & 0.000 & 0.00 & 100.00 \\
\hline & 10 & 0.93 & 0.94 & -0.011 & 0.011 & 1.06 & 98.94 \\
\hline & & Average & & -0.010 & 0.012 & 1.24 & 98.76 \\
\hline
\end{tabular}


\%Error $=$ Relative error $\mathrm{x} 100$

$$
\text { Relative error }=\left|\frac{X_{\text {Int }}-X_{\text {oscil }}}{X_{\text {oscil }}}\right|
$$

when $X_{\text {Int }}$ is the counting time from Robo-Boxing Trainer machine

$X_{\text {oscil }}$ is the counting time from the Digital Oscilloscope

$$
\text { \%Accuracy }=100-\% \text { Error }
$$

Secondly, the cutting-off sensor area tested for efficiency. The researcher separated the area on the punching target within three zones; the $1^{\text {st }}$ zone was the center of punching target, $2^{\text {nd }}$ zone was $7 \mathrm{~cm}$ either side of the punching target, and the $3^{\text {rd }}$ zone was $15 \mathrm{~cm}$ either side of the punching target. (Fig. 6) There were a total of 17 points to be tested on each punching target and the researchers pressed five times per point.

The results revealed the pressed force at the center of the punching target cut the signal from a total of 8 sensors. Researchers checked the cutting sensors' signal inside the machine. However, the percentage of precision ranged between 50 to 100 percentage. The 100 percentage of precision occurred in the total of 8 sensors to be cut-off simultaneously within 0.02 seconds. The range between 50 to 100 percentage of precision during the pressed force at the center referred to the sensors being cut-off from four to eight sensors simultaneously. For the tests in the 2 nd zone area, the sensors were cut-off ranging from 2-5 sensors and the percentage of precision was reported to range between 25 to 62.5 percent. For the tests on the $3 \mathrm{rd}$ zone area, sensors were cut-off only 1-2 sensors and the percentage of precision was reported between 12.5-25 percentage.

Thirdly, the researchers and the Sports Authority of Thailand's team evaluated the effectiveness of the Robo-
Boxing Trainer machine on a real-situation of a punching test. We recorded comments from a volunteer after the test. The volunteer had stated that the Robo-Boxing Trainer machine was comparable to a game simulation, in the essence that it was quite enjoyable. The volunteer added that it could also increase strength while managing to still be fun. One negative was that the surface area of the base-plate was too small, limiting the motion of each punch while using the machine.

\section{DISCUSSION}

Robo-Boxing Trainer machine gave the high accuracy of counting time. The results revealed that the percentage of error was 0 percentage and the percentage of accuracy was 100 percentage from the 10 seconds test. For the cutting time test, the average absolute different value was to 0.012 second and the percentage of accuracy was 98.8 percentage.

The cutting sensors' signal test revealed the high values of precision that occurred in the force of impact perpendicular to the center of punching target. It forced the punching target to move down and cut-off the signal in all sensors. For the punches at the A-target (left-hook punch), the C-target (righthook punch), and the D-target (upper-cut punch), they were rather difficult to get 100 percentage of precision because the force of impact was not perpendicular to the center of the punching target. The percentage of precision was up to no more than 50 percentage for these targets. Thus, meaning good precision in a real-situation.

Most volunteers suggested increasing the length of baseplate by at least 30 centimeters for footwork area. Regardless, Robo-Boxing Trainer proved to be an effective tool in aiding training for boxers. It showed to be a fun activity and also managed to improve performance.

For the further study, we are using this device to evaluate the norm of response time and precision of punch in Thai boxers (participation around 200 peoples). We will then apply it to study the relationship between the exhaustion and response time of the punch.

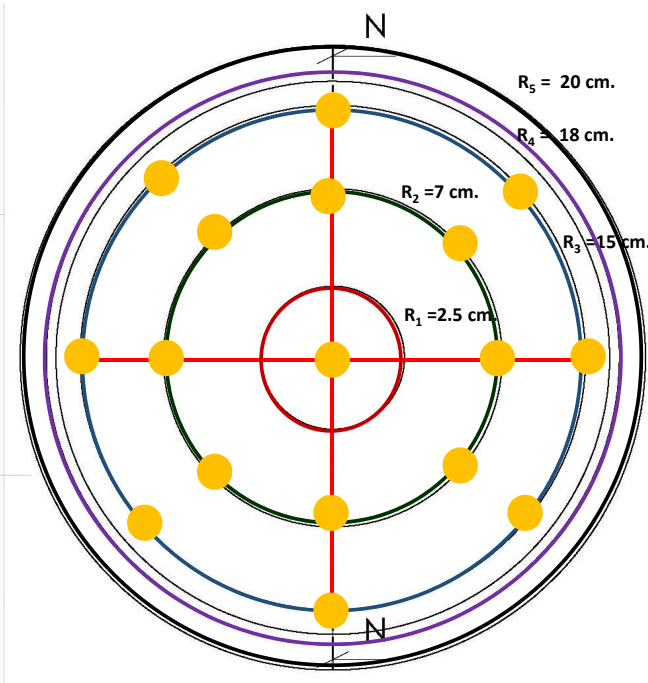

Fig. (6). Shows the point of pressed force on the punching target.

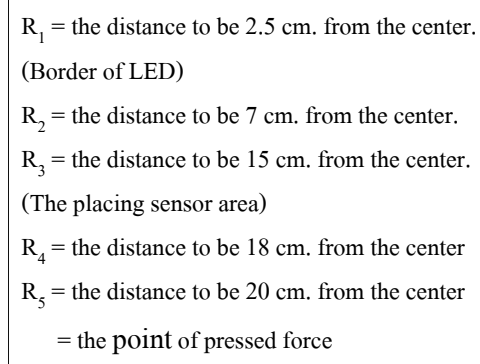




\section{CONCLUSION}

Robo-Boxing Trainer machine was a new way to evaluate continuously the response time (in seconds) and the precision of punches (in percentage). It could be used for enhancing a boxer's punching skills; such as the series of punch. This machine can aid the coach in assessing and aiding boxers in training and also apply it for other related sports.

\section{Practical Implication}

- This device can be applied to measure the precision of punch of a boxer.

- It can help train the speed of a boxer's punching skills.

- It helps to evaluate the speed of punching response by measuring the response time.

- The boxing trainer can apply it to create specific techniques through different punching series for his boxers.

- It can be applied in training the speed of hands and movement in other combat sports.

\section{ETHICS APPROVAL AND CONSENT TO PART- ICIPATE}

Not applicable.

\section{HUMAN AND ANIMAL RIGHTS}

No animals/humans were used for studies that are the basis of this research.

\section{CONSENT FOR PUBLICATION}

Not applicable.

\section{AVAILABILITY OF DATA AND MATERIAL}

The data that support the findings of this study are available from the corresponding author, [T. Jaysrichai], upon reasonable request.

\section{FUNDING}

None.

\section{CONFLICT OF INTEREST}

The authors declare no conflict of interest, financial or otherwise.

\section{ACKNOWLEDGEMENTS}

We would like to thank the Sports Authority of Thailand for the funding support. We would also like to thank Sports Science Research Division, Sports Authority of Thailand and Amateur Boxing Association of Thailand under the Royal Patronage of his Majesty the King. Finally, we would like to give thanks to our own workplace, Faculty of Physical Therapy.

\section{REFERENCES}

[1] M. Bianco, M. Ferri, C. Fabiano, F. Giorgiano, S. Tavella, U. Manili, M. Faina, V. Palmieri, and P. Zeppilli, "Baseline simple and complex reaction times in female compared to male boxers", J. Sports Med. Phys. Fitness, vol. 51, no. 2, pp. 292-298, 2011. [PMID: 21681165]

[2] D. Darby, J. Moriarity, R. Pietrzak, J. Kutcher, K. McAward, and P. McCrory, "Prediction of winning amateur boxers using pretournament reaction times", J. Sports Med. Phys. Fitness, vol. 54, no. 3, pp. 340-346, 2014. [PMID: 24739297]

[3] R.H. Burpee, and W. Stroll, "Measuring reaction time of athletes. research quarterly", Am. Phy. Edu. Assoc., vol. 7, no. 1, pp. 110-118, 1936.

[http://dx.doi.org/10.1080/23267402.1936.10761762]

[4] J. Hodgkin, Reaction time and speed of movement in males and females of various ages., vol. 8. 1937no. 1,

[5] S.P. Dube, S.U. Mungal, and M.B. Kulkarni, "Simple visual reaction time in badminton players; A comparative study", Natl. J. Physiol. Pharm. Pharmacol., vol. 5, no. 1, pp. 18-20, 2015. [http://dx.doi.org/10.5455/njppp.2015.5.080720141]

[6] N. Zarrouk, O. Hammouda, I. Latiri, H. Adala, E. Bouhlel, H. Rebai, and M. Dogui, "Ramadan fasting does not adversely affect neuromuscular performances and reaction times in trained karate athletes", J. Int. Soc. Sports Nutr., vol. 13, no. 18, pp. 1-10, 2016. [http://dx.doi.org/10.1186/s12970-016-0130-2] [PMID: 27099568]

[7] D. Darby, J. Moriarity, R. Pietrzak, J. Kutcher, K. McAward, and P. McCrory, "Prediction of winning amateur boxers using pretournament reaction times", J. Sports Med. Phys. Fitness, vol. 54, no. 3, pp. 340-346, 2014.

[PMID: 24739297]

[8] J. Moriarity, A. Collie, D. Olson, J. Buchanan, P. Leary, M. McStephen, and P. McCrory, "A prospective controlled study of cognitive function during an amateur boxing tournament", Neurology, vol. 62 , no. 9, pp. 1497-1502, 2004.

[http://dx.doi.org/10.1212/WNL.62.9.1497] [PMID: 15136671]

[9] J.A. Carlin, "Reaction time and force feedback system", United States Patent (US4763284A), 1986.

[10] W.P. Ebben, and D.O. Blackard, "Developing a strength-power program for amateur boxing", Strength \& Conditioning., vol. 19, no. 1, pp. 42-51, 1997.

[http://dx.doi.org/10.1519/1073-6840(1997)019<0042:DASPPF >2.3.C $\mathrm{O} ; 2]$ 